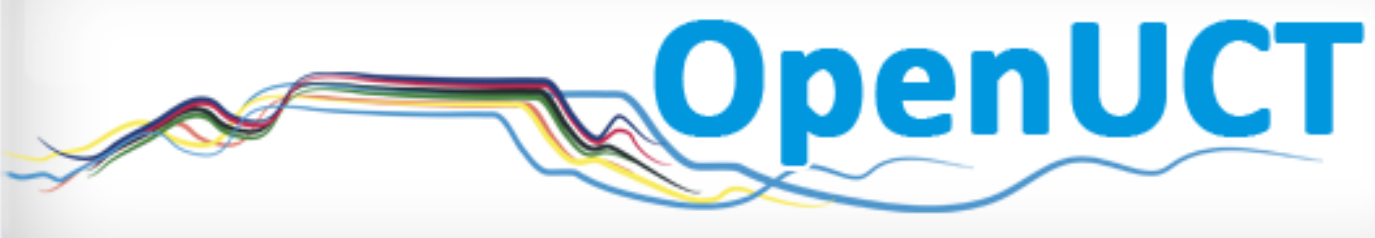

This is the author-approved manuscript version of a journal article published in:

Le Roux, K. 2008. A critical discourse analysis of a real-world problem in mathematics: looking for signs of change. Language and Education. 22(5): 307-326. DOI: 10.1080/09500780802152663.

It is made available under the terms of agreement between the author and the journal, and in accordance with the University of Cape Town's Open Access Policy for the purposes of research, teaching and private study.

http://www.openuct.uct.ac.za/sites/default/files/UCTOpenAccessPolicy.pdf 


\title{
A Critical Discourse Analysis of a Real-World Problem in Mathematics: Looking for Signs of Change
}

\author{
Kate Le Roux \\ Academic Development Programme, University of Cape Town, South Africa
}

\begin{abstract}
The concepts of 'access' and 'relevance' feature prominently in the discourse of change in mathematics education in South Africa. One way in which these concepts have been played out in mathematics classrooms is in the use of mathematical problems with real-world contexts. This paper presents a Critical Discourse Analysis of one such problem, selected from a first-year university access course in mathematics at a higher education institution in South Africa. Fairclough's three-dimensional model for the Critical Discourse Analysis is used to identify traces of different texts within this problem. The author argues that, in spite of evidence of texts that point to recent reforms in mathematics education and some possible signs of change, the mathematics text and the text of the school mathematical word problem remain dominant, and position the student in a particular way. The results of this analysis challenge some of the prevalent assumptions about 'access' and 'relevance' in mathematics education. The paper also highlights the potential for using Critical Discourse Analysis in mathematics education research.
\end{abstract}

Keywords: access, Critical Discourse Analysis, mathematics education, realworld problems, relevance, word problems

\section{Introduction}

\section{Change in mathematics education in South Africa}

Recent reforms in mathematics education in many countries portray new perspectives on what counts as mathematics and what it means to learn mathematics. In describing these changing perspectives, I draw on the work of Baker (1996), Forman (1996) and Moschkovich (2002a). Traditionally, mathematics has been presented as neutral and culture-free and as a silent, individual activity that involves completing procedures and solving traditional word problems. In contrast, reform curricula portray mathematics as a human activity with applications to real life. Learning mathematics involves collaborating, communicating and participating in mathematical practices such as modelling, making conjectures and proving.

Reform in mathematics education in South Africa post-1994 not only reflects features of curriculum reform internationally as described above, but was also driven by and continues to be driven by the urgent need to redress the 
inequalities of the past and to accelerate social and economic development. This reform has been characterised by calls for the promotion of access to the subject of mathematics and for an increased relevance of mathematics to students. Furthermore, reform in mathematics education has taken place in the context of often rapid and radical change in the education system as a whole, and in wider society in general. Consequently, mathematics education is both practiced and researched in a dynamic landscape. This is also a complex landscape where the legacy of Apartheid means that educational experience, language, class, race and poverty are often conflated. Yet, the ongoing change in the schooling system means that these relationships are not as clear as in the past (see for example Bangeni \& Kapp, 2007).

The research reported in this paper is situated within this complex and changing landscape. The focus of the paper is on the analysis of the text of a mathematics problem with a real-world context. The problem is taken from course material of a first-year university mathematics course (which I will call 'the course' from this point), designed to provide students with access to tertiary study in science at a South African university. I have two aims in presenting this paper. Firstly, I aim to analyse how mathematics education reform in South Africa, which is located in wider social change in the country, plays out in the text of a mathematics problem. More specifically, I set out to interrogate the related concepts of relevance and access as suggested by the textual analysis of the problem. Secondly, I aim to highlight the potential for using Critical Discourse Analysis as a methodology for studying reform in mathematics education, and to illustrate the value for mathematics education researchers of selecting theoretical and analytical tools from outside of the field of mathematics education.

\section{Relevance and access}

The concepts of relevance and access have been taken up in various ways in practice in maths education, two of which are appropriate in this paper.

A common interpretation of the term 'relevance' in the mathematics curriculum is as the application of mathematics in real-world situations (Nyabanyaba, 1999). In introducing the topic I have chosen commonly used definitions of the terms 'real-world' and 'real-world problem' while acknowledging that these terms are not unproblematic. Mathematics problems with real-world contexts range from those that can be classified as traditional word problems, to applications of mathematics, to problems that require mathematical modelling activity (International Commission for Mathematics Instruction (ICMI), 2002: 231). In this paper, I use the term 'real-world problem' broadly to refer to any mathematics problem that makes use of a real-world context. In using 'real-world', I am using the definition of 'real-world' adopted by the ICMI (2002: 230): The 'real-world' is defined as 'everything that has to do with nature, society or culture, including everyday life as well as school and university subjects or scientific or scholarly disciplines different from mathematics'. The precise nature of the real-world problem analysed in this paper and how it relates to other real-world problems will be discussed later in this paper. 
This particular interpretation of the notion of 'relevance' reflects a number of commonly held beliefs about the use of real-world contexts in mathematics (Boaler, 1993; Moschkovich, 2002b; Nyabanyaba, 1999), a number of which can be linked to views on access. Firstly, the belief that learning in context will enhance transfer between mathematics and the real-world; secondly that realworld contexts are a motivating factor for students and that they make the study of mathematics more interesting; thirdly that contextual problems require less higher order thinking than abstract mathematics, and are therefore good for weaker students.

However, a number of studies on the use of real-world problems in school mathematics challenge these beliefs and problematise attempts to make mathematics relevant. Firstly, on the level of ontology, these ideas have been criticised for the assumptions that they make about concepts such as 'real-world', 'school mathematics' and 'transfer' (Nyabanyaba, 1999; Ensor, 1997; Gerofsky in Thomas \& Gerofsky, 1997). Secondly, from a social practice perspective, many of these beliefs have been criticised for failing to recognise the situated nature of activities and the difference between the activity of classroom mathematics and everyday mathematical activity (Dowling, 2001, 1996; Cooper \& Dunne, 2000; Gravemeijer, 1997; Wyndham \& S" ljo, 1997; Baker, 1996; Sierpinska, 1995). There is a wealth of literature documenting how students fail to negotiate the boundaries between the real-world and school mathematics appropriately (Chacko, 2004; Cooper \& Dunne, 2000; Verschaffel et al., 2000; Wyndham \& S“" ljo, 1997). Thirdly, regarding the nature of problems with real-world contexts, much of the research at school level suggests that most of these problems do not actually require mathematical modelling-type activity and are designed merely for students to practice mathematical algorithms (Gerofsky, 1996; Gravemeijer, 1997; Sierpinska, 1995; Verschaffel et al., 2000). Lastly, and of particular interest in this paper, are a number of recent studies suggesting that real-world problems may prevent access to both the real-world and to the study of mathematics (Boero et al., 1995; Christiansen, 1997; Cooper \& Dunne, 2000; Dowling, 1996; Lerman \& Zevenbergen, 2004; Moschkovich, 2002a; Nesher \& Hershkovitz, 1997; Sethole, 2003; Sierpinska, 1995; Tobias, 2006).

One response to the challenge of providing students with access to the study of mathematics is for institutions to provide additional support for 'marginalised' students. I use the term 'marginalised' here as a broad term to refer to students who for various reasons such as educational background, language, social class or culture may be on the margins of the dominant culture of the particular institution. Since the 1980s, a number of higher education institutions in South Africa have attempted to provide additional support to school-leavers wanting to pursue tertiary studies. Different models of provision have been attempted (Pinto, 2001). For example, additional support may be in the form of a foundation course designed to prepare students for entry into higher education, or in the form of an extended curriculum in which students are provided with additional support and time in order to complete a tertiary qualification. Despite efforts to transform education at school level in South Africa since 1994, the reality is that the educational experiences of students currently completing school remain inequitable and success rates at tertiary institutions remain poor (South African Human Rights Commission, 2006; Scott, 2006). So the need for 
additional support remains. Furthermore, certain theorists have problematised the notion of access itself. On the topic of language access, Janks (2004) refers to the 'access paradox' when she argues that providing access to a dominant language perpetuates dominance of this language, yet denying students access to this language perpetuates their marginalisation. I suggest that 'language', as used in this argument, could be replaced with 'mathematics'. Baker (2005) argues that formal education actually conflicts with an access agenda; while pedagogic practices may be aimed at increasing access, there is a wealth of literature suggesting that they in fact privilege certain students and reproduce social difference.

\section{This paper}

The literature referred to in this discussion indicates that research has been done on real-world problems at school level. The setting of the work presented in this paper differentiates this work from much of the existing research. Firstly, it is located in the South African education system which has undergone rapid transition and remains in transition, from a system in which mathematics was used to exclude students, to one that promotes access and success for all students. Secondly, it is located in an undergraduate access course in mathematics, and hence is located at the interface between school and university mathematics. Lastly, the socio-political perspective of mathematics education adopted in this analysis distinguishes this study from most of the research already discussed. This perspective is used in this paper to investigate how the student is positioned by the text, and to investigate the possible consequences for students.

The work described in this paper is part of a wider study by the author that investigates the nature of a selection of problems with real-world contexts from the course, and examines how the practices used by students to solve these problems may be enabling or constraining. The latter examination will seek to address some of the issues raised in this paper.

In this paper, I begin with a brief description of the setting for the research; the mathematics course in which the research is located, my position as a researcher and a lecturer in this setting; and the real-world problem discussed in this paper. This is followed by an explanation of the conceptual framework and the analytic tools being used in the study. The body of the paper is taken up with the presentation of the findings, in the form of a description of the five texts, traces of which can be identified in the real-world problem. Lastly, I discuss these findings in relation to change and issues of access in mathematics education, and I relate these findings to other empirical studies.

\section{The Setting of the Research}

\section{The course}

The real-world problem discussed in this paper is taken from course material for a first-year university course in mathematics that forms part of an extended curriculum programme in the Science Faculty at a South African university. Students enrolled for the course are identified as having the potential to succeed at university, but may not satisfy the traditional university entrance criteria that 
are based solely on performance at the school-leaving examinations. The aim of the first two years of study is for students to establish a foundation in first-year courses, thus gaining access to future years of study. The minimum time for completion of an undergraduate science degree for students enrolled on the extended programme is four years. Initially, the focus of the course is on revision of topics in school mathematics that are required in the learning of calculus. Students then study limits, differentiation and integration. The teaching of the course has some features of more traditional classroom practice, such as four weekly lectures. Yet, many of the teaching methods are more consistent with classroom practices proposed by reform curricula. The course is taught in English, which is an additional language for more than half of the students (Visser, 2006).

\section{The researcher}

In undertaking the research for this paper, I have played a dual role as a mathematics education researcher and as a lecturer and course convenor of the course. When I began teaching on this first-year access course for the first time in 2004 , I was introduced to a course that already had a history, a wealth of accumulated course material and a relatively established teaching approach, all a product of that history. The course also differs greatly from my own experience of learning calculus at an undergraduate level. Encountering real-world problems such as the real-world problem discussed in this study (see Figure 1) for the first time, I felt a sense of unease about using these problems in my teaching. This sense of unease stemmed from my own lack of understanding: (a) of the role the real-world contexts were playing with regard to transfer and in relation to providing access to further study of mathematics and (b) the related issue of how the students were coping with the language demands of real-world problems.

My sense of unease about the use of these problems in the course was heightened when I undertook an analysis of a sample of course material, as reported in Bennie (2005). This analysis pointed to the course material that is rich in 'information transfer', with one of the three types of transfer identified as being transfer between mathematical and everyday contexts. The study recommended that further research be undertaken into the use of everyday contexts and language-based problems in the course.

This description of my complex position within the research setting is important, for Widdowson (1998) argues that any analysis is socially constrained. Pennycook (1996: 132) refers to Weedon (1987) when he claims that, 'to speak is to assume a subject position within a discourse and to become subjected to the power and regulation of the discourse'. In writing this paper, I am assuming a position within certain discourses. These discourses set out what I am able to think or say in the setting, and the choices I make are unavoidably, ideological. In conducting this research, I draw on my knowledge of the course developed during my involvement in the course over a three-year period. My knowledge of the wider social setting in which the course is located is based on my participation as a teacher and researcher in the field of mathematics education over a 15-year period. Furthermore, presentation of my findings to members of the research community in a variety of forums has enabled me to get feedback 


\section{The problem:}

The income, $C$, that the company Broadlows receives from sales depends on the amount $a$ that it spends on advertising. The income $C$ and the advertising expenditure $a$ are both measured in rands. Let $C=f(a)$.

(a) What does the company hope is true about the sign of $f^{\prime}(a)$ ? Explain!

(b) What does the statement $f(2000)=10000$ mean in practical terms?

(c) What does the statement $f^{\prime}(2000)=3$ mean in practical terms?

(d) Suppose that $f^{\prime}(2000)=0.5$. Would it be a good idea for the company to increase its spending on advertising? Explain your answer clearly.

\section{The worked solution:}

(a) $f^{\prime}(a)>0$ : This will mean that the income is an increasing function of the advertising expenditure, i.e., as the amount spent on advertising increases, so does the income.

(b) If R2000 is spent on advertising, then the income is R10 000.

(c) When R2000 has been spent on advertising, the income is increasing by R3 per rand spent on advertising. This means that when $\mathrm{R} 2000$ has been spent on advertising the income generated by the next rand spent on advertising will be R3, i.e. income will increase by $\mathrm{R} 3$ for every R 1 spent on advertising.

(d) No, an increase in R1 on advertising will result in an increase of only $50 \mathrm{c}$ in income, an overall loss.

Figure 1. The problem text (adapted from Hughes-Hallet et al., 1994: 125)

on my analysis and interpretation, and to discuss possible alternatives to my interpretations.

\section{The problem text}

The real-world problem to be discussed in this paper (which I refer to as the 'problem text' in the rest of this paper) is given in Figure 1. This problem is used 11 weeks into the academic year when students have been introduced to the mathematical concept of rate of change. My experience of teaching on this course over the past three years as well as research on the course material suggests that this problem is typical of the real-world problems in the course itself (Bennie, 2005). In lectures and workshops, students answer rate of change questions with similar mathematical structure, but with varying problem contexts such as population growth, chemical reactions and sales.

In selecting the analysis of this one problem for discussion in this paper, I am able to present much of the detail of the analysis, thus serving the intended aim of illustrating the potential for using Critical Discourse Analysis in mathematics education. Both the problem and the worked solutions (which are provided to students a few days after the Workshop) were analysed for this study as it was felt that the solutions would provide additional information on the discourses at work in the setting and suggest how the student is positioned by the problem text. 


\section{Conceptual Framework}

\section{'Social practice' perspectives on language and mathematics}

In viewing language use as 'social practice', I draw on the work of the New Literacy Studies movement and writers such as Gee (2005), Fairclough (1992, 2003 ) and Street $(1993,2005)$. From the 'social practice' perspective, language is situated within a social setting, and is thus linked to culture and power. In this paper, I use the term 'social practice' as a broad term that includes economic, cultural and political practices. I choose to define discourse in the abstract sense as suggested by Fairclough (1992: 62), that is, as 'spoken or written language use' which is linked to other non-language forms of social life. From this perspective, discourses are not mutually exclusive and fixed, but can overlap, can be contested and can change. Similarly, texts as examples of written language use, may be overlapping, dynamic, and contested. Fairclough also uses the term 'discourse' more specifically as a noun, as discussed below under 'Methodology'.

Consistent with my approach to language as a 'social practice', is the view of mathematics as 'social practice'. In this view, mathematics is learned and used in social settings which are linked to culture, politics and ideology (Baker, 1996). The social practice perspectives on language and mathematics mean that the language use in mathematics is not restricted to using appropriate grammar and vocabulary, but involves using the specialised language of mathematics. Furthermore, Setati (2005) argues that two forms of English may be used in a mathematics classroom in which English is the language of learning and teaching; mathematical English (the English mathematical register or the specialised language of mathematics) and ordinary English.

I feel that the "social practice" perspectives on language and mathematics are appropriate in the South African setting, given studies highlighting that these practice have not been neutral and value-free in the past (Khuzwayo, 2005; Setati, 2005; Vithal \& Volmink, 2005).

\section{Methodology}

Fairclough's three-dimensional model for Critical Discourse Analysis

The conceptual framework described above makes it both possible and necessary to link written text to wider social practices. I have thus chosen to use Fairclough's three-dimensional model for Critical Discourse Analysis (1992) as a framework for studying the relationship between the written text of a mathematics problem, the associated discursive practices (the processes of text production, distribution and consumption of the text) and the wider social practice of which the discursive practices form part (see Figure 2). In this section, I discuss the concepts that I use in the analysis; text production, distribution and consumption, the functions of text, intertextuality and orders of discourse.

\section{Text production, distribution and consumption}

On the level of discursive practice in Fairclough's three-dimensional framework, the analysis focuses on the processes of production, distribution and consumption of the text. There may be one or more 'producers' of a text. The 


\section{SOCIAL PRACTICE}

\section{DISCURSIVE PRACTICE (production, distribution and consumption)}

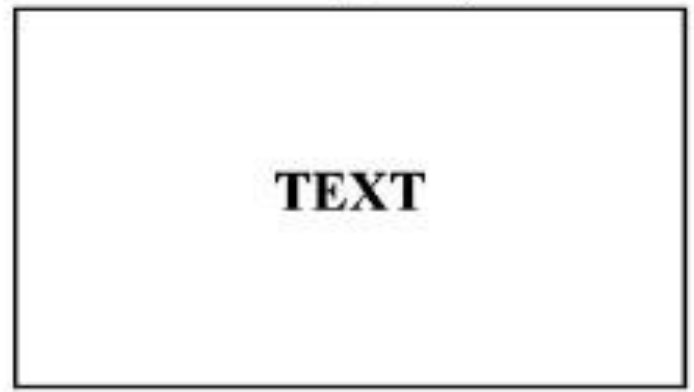

Figure 2 Fairclough's three-dimensional framework (1992)

producer of the problem text analysed in this paper is taken to be both the author of the textbook from which the problem was originally selected and the course lecturer who selected the problem for use in the course material. The 'consumer' or the 'interpreter' of the mathematics problem is taken to be the student who is solving the problem, who I have chosen to call the 'interpreting student' in this discussion.

Fairclough (1992: 134) argues that texts constitute subjects in the sense that text producers 'interpellate' interpreting subjects who are capable of making the relevant assumptions about the text, and hence, a coherent reading of the text. So, the producer of the problem text will have a particular student in mind when setting the problem. Fairclough (2003) notes that all texts make assumptions, and that certain things are left implicit. A successful solution to the problem text will depend on there being some shared meaning between the producer and the interpreting student.

\section{The functions of text}

A study of the processes of production, distribution and consumption of texts on the level of discursive practice as described above, makes it possible for me to consider the function or the meaning of a text. Fairclough (2003: 27) identifies three types of meanings in text: 'Representation' refers to what the text says about the world; 'Action' refers to how the text establishes social relations; 'Identification' refers to what the text says about the attitudes, beliefs and values of the participants. Through these meanings, a text is linked to wider social and political practices.

\section{The concept of intertextuality}

In analysing the problem text, I enter the text on the level of discursive practice and explore the processes of text production, distribution and consumption. To do this, I have chosen to use Fairclough's concept of intertextuality. Fairclough 
(1992: 84) argues that 'texts are full of other texts'. To identify these texts, I refer to the inner level of Fairclough's three-dimensional model, that is, the written text.

The concept of intertextuality enables me to identify certain conventions or elements that form part of the discursive practice. Fairclough $(1992,2003)$ distinguishes a number of related elements, namely genre, activity type, style, register and discourse. These elements are relatively stable ways of representing, acting and identifying, and they indicate how language can be used in a particular area of social life. I have chosen to use these terms, bearing in mind Fairclough's (1995) acknowledgement of the difficulties of identifying and naming these elements. Fairclough (2003) argues that the three meanings of a text ('Representation', 'Action' and 'Identification' described above) can be linked to these elements.

\section{Order of discourse}

Fairclough (1992) suggests that texts have a history and they transform prior texts into the present. This transformation can be conventional and routine in that conventions are retained and reproduced unchanged, or it can be productive and creative if conventions are restructured. The productivity is not, however, unlimited but is socially constrained. Thus, the concept of intertextuality provides a link to the outer level of Fairclough's three-dimensional framework that allows me to study discursive change in the context of wider social change.

In particular societies or institutions, the elements named above, that is, genre, activity type, style, register and discourse, will be ordered in particular ways in relation to one another. This ordering is what Fairclough calls an 'order of discourse' (Fairclough, 1995: 12). Fairclough (1992: 97) explains that 'change leaves traces in texts in the form of the co-occurrence of contradictory or inconsistent elements'. By identifying instances of continuity or change in the text, one is able to explore change in discursive practice, and possibly, in the wider order of discourse.

\section{Findings}

Using the concept of intertextuality and entering the problem text on the level of discursive practice (the middle level of Fairclough's three-dimensional framework), I was able to identify traces of five different texts in the problem. In the section that follows, I discuss each of these five texts by pointing to features of the problem text that provide evidence for the presence of each different text (the inner level of Fairclough's three-dimensional framework). I also use my knowledge of the context to relate the presence of traces of each of these five texts to the wider social context in which the problem text is situated (the outer level of Fairclough's three-dimensional framework). It should be noted that the naming of the texts for example, the 'business text' has been done for convenience in discussing the features of the problem text and is based on the researcher's understanding of the wider elements associated with these texts. The same point can be made about the naming of elements, for example, the 'access discourse' and the 'mathematics register'. As noted, from a social practice 
perspective, these concepts are not mutually exclusive, are dynamic and can be contested.

\section{The business text}

The first sentence of the problem text signals to the reader that this is a problem about the sales and the advertising strategy of a company, thus suggesting a text about business. On the inner level of Fairclough's three-dimensional framework, four features of the written text suggest a particular view of business. Firstly, the present tense ('receives' and 'depends on') is used to state that the company's sales depend on its advertising expenditure, thus lending authority to this statement about the functional relationship between advertising expenditure and income from sales (Fairclough, 1992). Secondly, the use of the definite article 'the' in the phrases 'the income' and 'the company' limits the context to this particular company, 'Broadlows', thus excluding the possibility of considering a different company in which there may be a different relationship. Thirdly, the use of the word 'receives' in sentence 1 removes the agency and responsibility of the specific company 'Broadlows'. The use of the passive voice in sentence 2 also makes the agency of the company vague (Fairclough, 1992). Thus, the functional relationship between income from sales and the advertising expenditure appears natural. The human agency in the economic production is ignored, and issues such as fair labour practices and environmental impact are not mentioned. Lastly, the functional relationship between the income from sales and the advertising expenditure is foregrounded. Any other possible influences on the income from sales of the company are silenced.

The four features of the written text point to a particular element on the level of discursive practice in Fairclough's three-dimensional framework. I have chosen to call the element a 'profit-driven business discourse'. The first two sentences perform an identification function in the text, in that, they portray a profit-driven view of business. These two sentences of the text construct the producer and the interpreting student in a particular way. They perform an 'action' function as the producer of the text is given the identity as the authority in relation to the interpreting student, and this student is constituted as the student who will buy into this 'profit-driven business discourse'.

This analysis of the problem text is reinforced by an analysis of the worked solutions for this problem. In order to provide the 'correct' answers for questions (a) and (d), the interpreting student will have to buy in to the profit-driven business discourse. A company with a profit-driven motive will want an increase in advertising expenditure to result in an increase in income from sales. The company will not want a situation in which an increase in R1 on advertising results in an increase of only $50 \mathrm{c}$ in income. Not only is the interpreting student expected to draw on some knowledge of business, but is also expected to draw on knowledge of a particular type of business discourse, that is, a profit-driven business discourse.

Moving to the social practice level of Fairclough's three-dimensional framework, the use of a business context in a mathematics problem reflects a trend in mathematics education, both in South Africa and elsewhere to include realworld contexts in mathematics. In the South African context, it is possible to 
identify certain discourses which provide some of the 'history' behind the production of this text. Firstly, the 'reconstruction-and-development discourse' is characterised by calls for South Africa to become more productive economically, and the accompanying call for improvements in mathematics, science and technology education. This can be linked to the common belief that skills developed in school mathematics can be transferred to other settings, such as the world of work (Boaler, 1993; Moschkovich, 2002b). Secondly, the 'access discourse' is characterised by calls for access to quality education and claims that the knowledge of mathematics is a human right. This discourse can be linked to prevalent beliefs about the value of contextual problems for students and particularly for weaker students (Boaler, 1993; Moschkovich, 2002b). Thirdly, the 'calculus reform discourse' is based on the ideas of the 'Calculus Reform Movement'. I use the term 'Reform Calculus Movement' as a broad term to describe a number of projects initiated in the late 1980s, in an attempt to reform the teaching and learning of calculus. This discourse underplays the more abstract and analytic approaches to teaching calculus, in favour of the use of conceptual understanding, flexibility in moving between different representations and the solving of applied problems. The initial design of the course that provides the setting for this study was influenced by the ideas of this Movement.

The description of these three discourses suggests possible ways that the interpreting student may be positioned by the problem text: firstly, as a student who needs to go into the world to be economically productive; secondly as a person who has an interest in and has some knowledge of business (although a particular type of business); thirdly, as a student who may find the context useful in gaining access into more abstract mathematics.

\section{The science text}

I begin the discussion by referring to the inner level of Fairclough's threedimensional framework for textual evidence of the science text. Sentence 1 contains many content words or words that contain a lot of information: the name of the company, business concepts such as 'income' and 'advertising', the relationships between these concepts and symbols such as $C$ and a that represent the concepts. This sentence could be said to be 'lexically dense', a feature of scientific writing (Halliday, 1993: 76). As noted earlier, in sentences 1 and 2, the agency of the company 'Broadlows' is removed, and the functional relationship between the income and the advertising expenditure is foregrounded. This absence of agency is also a feature of scientific writing (Lemke, 1990). The use of metaphor also contributes to an absence of human agency. The company 'Broadlows' is personified, as suggested by the words 'receives', 'spends', 'hopes', etc. Thus, the company appears as one entity, and not a company run by individual people. This absence of agency is also created through the nominalisation 'advertising' in sentence 2, another feature that is typical of scientific writing (Halliday, 1993). In this case, the person responsible for the spending on advertising is hidden.

There are also traces of scientific writing in the worked solutions to the problem. Conditional statements such as 'If R2000 is spent on . . .' (question (b)) and 'When R2000 has been spent. . .' (question (c)) imply that certain logical relations are being assumed. 
On the level of discursive practice in Fairclough's three-dimensional framework, the features of the text described here signal to the interpreting student that this text is not just about business. I have chosen to use the term 'academic scientific discourse' to name the element suggested by these textual features. This is a broad term that may encompass a number of genres, styles and other discourses. For example, the mathematics register discussed below is regarded as a subsection of this broader discourse. On the level of social practice in Fairclough's three-dimensional framework, the text plays an identification role in that it is suggestive of the nature of science. Through the features of the text discussed above, this science text is linked in history to other science texts.

\title{
The mathematics text
}

There are a number of features of the problem text (Figure 1) that indicate that this is a mathematics text. I have chosen to call this element the 'mathematics register', in the sense used by Halliday (as quoted in Pimm, 1987: 76):

\begin{abstract}
We can refer to a 'mathematics register', in the sense of the meanings that belong to the language of mathematics (the mathematical use of natural language, that is, not mathematics itself), and that a language must express if it is used for mathematical purposes ... we should not think of a mathematical register as consisting solely of terminology ...
\end{abstract}

I am regarding the mathematics register as subset of the wider 'academic scientific discourse' described above. There is thus some overlap in the textual features that point to the mathematics text and the science text discussed above, for example, the absence of agency. There are, however, some features discussed here that are unique to the mathematics register.

The first two sentences of the problem text may contain traces of a business text, but sentence 3 gives the text coherence as a mathematics text, and it is clear from this sentence that the student is expected to make a particular reading of the first three sentences of the problem (Fairclough, 1992). The symbols $C$ and a, which are ordinary letters of the alphabet, are foregrounded through their use and repetition in sentences 1 and 2 . In sentence 3 , the statement $C=f(a)$ gives the relationship between these symbols, indicating that this is a mathematics text about functions and functions in one variable in particular. This justifies the choice of a capital $\mathrm{C}$ and a lower-case a in sentences 1 and 2, as it is clear that they were chosen with mathematical function notation in mind. Pimm (1987) notes that differences in alphabet and fonts in the mathematics register indicate conceptual differences, in this example, the lower-case a represents the independent variable and the capital $C$ represents the dependent variable. The conditional statement 'Let . . .' in sentence 3 is typical of the mathematics register, and as noted by Pimm (1987), is a grammatical construction not often used in ordinary English (another example is 'Suppose that ... ' in question $7(d))$.

The phrase 'depends on' in sentence 1 is a phrase used in everyday English. Yet, sentence 3 suggests that the interpreting student is expected to interpret this phrase in a particular way, that is, as a functional relationship in one variable, and that, in this problem, the income depends only on the advertising 
expenditure, and on no other factors. Pimm (1987: 78) argues that the 'most striking' characteristic of the mathematics register is the number of terms in this register that are borrowed from everyday English. Other words in the problem text borrowed from ordinary English, but with meanings peculiar to the mathematics register are 'sign' (question (a)) and 'increasing function' (solutions to question (a)).

There are a number of other pointers to the mathematical register, for example, the use of the conditional statement 'If . . . then' (solution to questions (b)) and the use of the punctuation symbol in $f(a)$ (question (a)). Pimm (1987) notes that the punctuation symbol in $f(a)$ modifies the functional relationship $f(a)$ : $f(a)$ is the function obtained from $f(a)$ by the process of differentiation.

The textual features discussed here perform an identification function, as they indicate to the interpreting student that: (a) the problem text should be read as a mathematics text and (b) that students should respond by producing a solution that is also a mathematics text. They also perform an action function as they constitute the producer as a textbook author/mathematics teacher and the interpreting student as a student of mathematics. In terms of distribution on the level of discursive practice in Fairclough's three-dimensional model, the two texts (the problem and the worked solution) form a chain of texts that is predictable in the mathematics classroom: the producer has selected a mathematics problem which the interpreting student must solve by producing an appropriate mathematics text.

\section{The school mathematical word problem text}

In this section, I refer to features of the problem text that suggest an element which I refer to as the school word problem genre. Fairclough (1992: 126) describes a genre as 'a relatively stable set of conventions that is associated with, and partly enacts, a socially ratified type of activity'. Gerofsky (1996) classifies school word problems as a genre, and I use her classification in this discussion. This genre has a 'history'; the use of word problems in mathematics can be traced back 4000 years to ancient Babylonian and Egyptian cultures (Gerofsky, 1996). This text is thus linked to many texts that have preceded it.

Returning to the inner level of Fairclough's three-dimensional framework. The name of the company 'Broadlows' hints, possibly in a humorous way, at the well-known furniture company in South Africa called 'Bradlows', thus suggesting a text about business. This re-naming of the company may be an attempt to avoid copyright issues, yet it suggests that the problem is not really about real-world business. Furthermore, there are no sources used to back-up the claim about the functional relationship between the income and the advertising expenditure. The instruction 'Suppose that ... ' in question (d) suggests that the student is only expected to pretend that the given situation is the case, and not to expect that this refers to a real-life situation. These textual features suggest that the business context has no 'truth value' and does not really refer to realworld objects (Gerofsky, 1996: 39). They perform both an identification and an action function by suggesting a relationship between the student and the real world, that is, that the student need not consider the real world in answering the question. Gerofsky (1999: 37) claims that, 'word problems imitate and recall 
other word problems, not our lived lives', thus pointing to the historical chain of texts to which a word problem belongs.

A number of other features of the text perform an identification function and give the text coherence as a school word problem. These features also perform an action function by constituting the interpreting student as a student in a mathematics classroom. The student is positioned as a student who is able to select from the real-world context, the relevant abstract mathematics for solving the problem.

Gerofsky (1996: 37) points out that most word problems follow the same structure of 'set-up', 'information' and 'questions'. In the problem, text sentences 1,2 and 3 provide the context and the information needed to answer the question (the 'set-up' and the 'information'). Sentence 3 is followed by questions directed at the student (the 'questions').

The style of the problem text also hints at the structure of a word problem. As noted in earlier discussion, sentences 1 and 2 are given in the form of statements and the producer of the text is hidden. There is a change of style in sentence 3 ('Let $\mathrm{C}=\mathrm{f}(\mathrm{a})$ ), which is an instruction to the interpreting student. Again, this gives the student an identity of a student who must produce a mathematical response, approved of by the mathematics teacher.

There is a change of tenses in the problem text. The introductory sentences describe the company in the present tense ('receives', 'depends', etc.). This tense is continued in questions (a) to (c). The tense changes in question (d), in which the student is instructed to 'suppose' and to consider what will happen in the future: 'Would it be a good idea for the company to increase . . . ?' Gerofsky (1996: 41) argues that such tense changes are not perceived as a problem in mathematical word problems as they point to

... an 'understanding' between writer and reader that these supposed situations do not have truth value, and that the writers' intentions and the readers' task are something other than to communicate and solve true problems.

\section{The explaining text}

Cobb (in Sfard et al., 1998: 46) distinguishes between a 'calculational discourse' (a conversation in which the primary topic of conversation is the calculation processes) and a 'conceptual discourse' (a conversation in which the reasons for the calculations are made explicit). Working on the inner level of Fairclough's threedimensional framework, a number of textual features of the problem suggest that the text aims at a conceptual discourse. Firstly, in questions (a) and (d), students are required to 'explain' their reasoning. Secondly, all the questions require that students give the meaning of mathematical concepts (the function and its derivative). No calculations are required, or even possible, since no formulae for the functions are given. These textual features perform an identification function as they indicate what the text producer values. They perform an action function as they position the interpreting student as a person who is expected to understand and explain the meaning of the concepts.

The attempt to encourage a conceptual discourse in the problem text reflects wider worldwide reforms in mathematics education that are aimed at 
encouraging mathematical understanding, rather than proficiency in calculations alone. This conceptual discourse can also be linked to the 'calculus reform discourse' mentioned earlier in this discussion, a discourse which promotes understanding of mathematical concepts.

\section{Discussion}

In this section, I use the presence of the five texts as identified and described in the findings to discuss the notions of change and access in mathematics education. I also relate my discussion to the results of other relevant research.

\section{The order of discourse and change}

Using the concept of intertextuality, I have identified traces of five texts in the problem text, namely the 'business text', the 'science text', the 'mathematics text', the 'school mathematical word problem text', and the 'explaining text'. Each of these texts has a history, and can be linked to one or more elements such as discourses and genres, and hence, to wider discursive and social practice. Having identified these elements, it is possible to reflect on how they are organised or ordered. For example, the 'profit-driven business discourse' can be related to the 'reconstruction and development discourse', 'access discourse', and the 'calculus reform discourse'; and the 'conceptual discourse' can be linked to the 'calculus reform discourse'. These discourses have featured prominently in mathematics education reform in the past decade, and can be linked to wider changes in mathematics education worldwide as well as to social and political changes in South Africa. The identification of these discourses hints at the possibility of transformation and change in mathematics education, as the text of a mathematics problem contains traces of number of different texts.

However, this analysis suggests that the mathematical register (which is a part of the wider scientific academic discourse) and the school mathematical word problem genre remain the dominant elements in the problem text, and that there is, in fact, little change. In terms of distribution on Fairclough's level of discursive practice, the problem text is linked to the mathematics texts that have been solved by the students in the class so far and to traditional school word problems in particular. There is, however, one possible sign of change from a more traditional mathematics text, and this is suggested by the attempt to encourage a conceptual discourse rather than a calculational discourse. The student cannot simply apply a mathematical procedure recently done in class, as is usually the case in school word problems, but must rely on his/her understanding of the mathematical concept of rate of change.

\section{Positioning and access}

The interpreting student is positioned in a particular way by the problem text. Firstly, in order for the student to understand the problem (the receptive level), $\mathrm{s} /$ he needs to be able to interpret the use of the mathematics register. Secondly, on the productive level, the interpreting student needs to be able to use the mathematics register appropriately in order to produce the correct solution (as indicated by the worked solutions for the problem text). Thirdly, the presence of 
the school mathematical word problem genre sends a message to the interpreting student about the truth value of the context, as many aspects of the business context are not relevant when solving this mathematics problem. Yet, those aspects of the business context that are relevant require that the student buy in to the 'profit-business discourse'. Lastly, the student has to have a conceptual understanding of the mathematical concept of rate of change.

According to Fairclough (1992), a reading of a text will depend on the interpretative principles used. Given the setting of this research, I would add that a reading of the text and the production of an answer considered appropriate in the setting will also depend on the language resources brought to the setting. The question we need to ask in relation to the problem text therefore is, "Which students will use the appropriate interpretative principles for the context?', and 'Which students will have the appropriate language resources for the context?' The answers to these questions are vital, given that this problem text is taken from a course that is specifically designed to provide marginalised students with access to tertiary study in the sciences. The analysis of the text of one real-world problem in mathematics is not sufficient to answer these important questions; yet, this analysis highlights a number of important issues for consideration. These issues will form part of the study of student responses when answering this and other texts, the main feature of the wider study.

Firstly, I have argued in this paper that the mathematics register is dominant in the text of the problem. This needs to be considered in the context of Setati's (2005) arguments about mathematical English and ordinary English; she lists the many ways that these two forms can be confused (see also Pimm, 1997 and Monaghan, 2007), and argues that this confusion may be more acute for students learning mathematics in English as an additional language. The analysis of the problem text points to the need for students to use logical connectives such as 'If . . . then' in responding to the problem text. Research points to the difficulties English additional language speakers have with logical connectives, regarded as particularly important in understanding and learning mathematics (Dawe, 1983; Monaghan, 2007). More generally, Barton and Neville- Barton (2003) claim that undergraduate students who are learning English as an additional language suffer a greater disadvantage in mathematics (about 10\%) than students for whom English is their home language, and that the technical language of mathematics is particularly problematic for these students.

Secondly, although the mathematics register may dominate the problem text analysed in this paper, certain questions require that students use 'practical terms' to explain their understanding of mathematical concepts. So, not only are students being required to acquire the use of mathematical English, but sometimes they are required to resort to ordinary English to explain the mathematical concepts. In her study of an undergraduate geology course, Clark (2006) argues that, while the ability to express something 'in your own words' is often regarded as a measure of understanding, requiring this for a student may ultimately limit access to the discipline.

Thirdly, I have argued that the presence of traces of a conceptual discourse in the problem text distinguishes this text from more traditional mathematical word problems. Setati $(2002,2005)$ argues that engaging in a conceptual discourse is linguistically demanding. In her research, she reports that students 
who did not have the necessary English fluency to take part in conceptual discourse remained silent or answered using procedural discourse.

Lastly, I have argued that students who perform successfully on this problem need to have access to the school mathematical word problem genre and the associated assumptions. Given the different and often inequitable experiences that South African students currently experience in relation to school provision, it is possible that students entering tertiary studies will have varying experiences of school word problems. Dowling (1996) and Sethole $(2003,2005)$, who work in the South African setting, claim that the use of real-world problems may result in differential access both to mathematics and to the everyday. Also working in South Africa, Tobias (2006) has suggested that some students may be marginalised from the genre of school mathematical word problems. Furthermore, Cooper and Dunne (2000) have linked the differential performance to class, arguing that working-class and intermediate-class students perform less well on realistic items than the service-class children, in comparison to their performance on purely mathematical items. Given the complexities of the relationship between race, language, social class and educational provision in South Africa, these research claims need to be investigated further in the wider research project of which this textual analysis forms part. For it may be that certain students, on the grounds of language and social class, are doubly disadvantaged in gaining access to mathematics, and as suggested by Baker (2005), a system which aims to promote access may, in fact, be reproducing a difference.

\section{Conclusion}

In this paper, I have presented the use of Fairclough's three-dimensional model for the Critical Discourse Analysis of a mathematics problem taken from a course designed to give marginalised students access to tertiary studies in the Sciences. Traces of texts from discourses outside of the traditional mathematics education hint at a transformation of the traditional mathematics problem. The presence of these texts points to recent attempts to make the mathematics curriculum more relevant and accessible than it has been to students in the past. In particular, the presence of the 'explaining text' in this word problem suggests a move away from a procedural approach which is typical of traditional school mathematical word problems, towards a promotion of conceptual understanding.

However, the analysis also points to the reproduction of the traditional school mathematics word problem in which the context is regarded as less important than the mathematical structure and content. The interpreting student is positioned as a student of mathematics who has access to the use of the mathematics register and to the assumptions associated with the school mathematical word problem genre.

The analysis presented in this paper is limited to just one problem and is limited by the socially constrained nature of the researcher's interpretations. However, it does demonstrate the usefulness of Fairclough's three-dimensional model as a framework for analysing problems of this nature. The in-depth nature of the Critical Discourse Analysis has enabled me: (a) to question whether the envisaged change in mathematics education is played out in such a problem 
and (b) to question assumptions about using real-world contexts in mathematics and about the notions of relevance and access. This questioning, together with the existing research on the learning mathematics in English as an additional language and on the use of real-world problems in school mathematics, suggests that certain students targeted for access may actually have difficulty with real-world problems. The next part of the study, which involves investigating how students solve this and other real-world problems from the course, will investigate these issues further.

\section{Acknowledgements}

The author acknowledges feedback from colleagues in the Centre for Research in Engineering Education (CREE) and the Centre for Higher Education Development (CHED) both at the University of Cape Town, and the Maths Education PhD students at the University of the Witwatersrand. In particular, the author thanks Jill Adler, Moragh Paxton, Mamokgethi Setati, Lucia Thesen and Ermien van Pletzen for their ongoing advice. Financial assistance of the National Research Foundation (NRF) for this project is gratefully acknowledged.

\section{Correspondence}

Any correspondence should be directed to Kate Leroux, Maths and Applied Maths, University of Cape Town, Private Bag X01, Rondebosch 7701, South Africa (kate.leroux@uct.ac.za).

\section{References}

Baker, D.A. (1996) Mathematics as social practice. In K. Morrison (ed.) Proceedings of the Association for Mathematics Education of South Africa Second National Congress (Vol.1, pp. 1-19). Cape Town: AMESA.

Baker, D.A. (2005) Access and equal opportunities: Is it sufficient for maths and social justice? In Focus Talk, presented at the Adults Learning Mathematics (ALM) Conference. Melbourne, Australia.

Bangeni, B. and Kapp, R. (2007) Shifting language attitudes in a linguistically diverse learning environment in South Africa. Journal of Multilingual and Multicultural Development 28 (4), 253-269.

Barton, B. and Neville-Barton, P. (2003) Investigating the relationship between English language and mathematical learning. In Proceedings of the Congress of European Research in Mathematics Education. Pisa, Italy: University of Pisa.

Bennie, K. (2005) The MATH taxonomy as a tool for analysing course material in mathematics: A study of its usefulness and its potential as a tool for curriculum development. African Journal of Research in Mathematics, Science and Technology Education 9, 81-96.

Boaler, J. (1993) The role of contexts in the mathematics classroom: Do they make mathematics more 'real?' For the Learning of Mathematics 13 (2), 12-17.

Boero, P. et al. (1995) Aspects of the mathematical-culture relationship in mathematics teaching-learning in compulsory schooling. In Proceedings of the 19th Conference of the International Group for the Psychology of Mathematics Education. Recife: PME. http://macosa.dima.unige.it/pup/pme/pme.htm. Accessed 12.6.06.

Chacko, I. (2004) Solution of real-world and standard problems by primary and secondary school students: A Zimbabwean example. African Journal of Research in Mathematics, Science and Technology Education 8 (2), 91-103.

Christiansen, I.M. (1997) When negotiation of meaning is also negotiation of task: Analysis of the communication in an applied mathematics high school course. Educational Studies in Mathematics 34 (1), 1-25. 
Clark, S. (2006) 'Use your own words' - impossible exhortations. In L. Thesen and E. van Pletzen (eds) Academic Literacy and the Languages of Change (pp. 53-66). London: Continuum.

Cooper, B. and Dunne, M. (2000) Assessing Children's Mathematical Knowledge: Social Class, Sex and Problem-Solving. Buckingham: Open University Press.

Dawe, L. (1983) Bilingualism and mathematical reasoning in English as a second language. Educational Studies in Mathematics 14 (3), 325-353.

Dowling, P. (1996) A sociological analysis of school mathematics texts. Educational Studies in Mathematics 13, 389-415.

Dowling, P. (2001) Mathematics education in late modernity: Beyond myths and fragmentation. In B. Atweh, H. Forgasz and B. Nebres (eds) Sociocultural Research on Mathematics Education: An International Perspective (pp. 19-36). Mahwah, NJ: Erlbaum.

Ensor, P. (1997) School mathematics, everyday life and the NQF; a case of nonequivalence? Pythagoras 41 (1), 36-44.

Fairclough, N. (1992) Discourse and Social Change. Cambridge: Polity.

Fairclough, N. (1995) Critical Discourse Analysis: The Critical Study of Language. London: Longman.

Fairclough, N. (2003) Analysing Discourse: Textual Analysis For Social Research. London: Routledge.

Forman, E.A. (1996) Learning mathematics as participation in classroom practice: Implications of sociocultural theory for educational reform. In L.P. Steffe and P. Nesher (eds) Theories of Mathematical Learning (pp.115-130). Mahwah, NJ: Erlbaum.

Gee, J. (2005) An Introduction to Discourse Analysis. London: Routledge.

Gerofsky, S. (1996) A linguistic and narrative view of word problems in mathematics education. For the Learning of Mathematics 16 (2), 36-45.

Gerofsky, S. (1999) Genre analysis as a way of understanding pedagogy in mathematics education. For the Learning of Mathematics 19 (3), 36-46.

Gravemeijer, K. (1997) Solving word problems: A case of modelling? Learning and Instruction 7 (4), 389-397.

Halliday, M.A.K. (1993) Some grammatical problems in scientific English. In M.A.K. Halliday and J.R. Martin (eds) Writing Science: Literacy and Discursive Power (pp. 6985). London: Falmer.

Hughes-Hallet, D. et al. (1994) Calculus. New York: Wiley.

International Commission for Mathematics Instruction (ICMI) (2002) Study 14: Applications and modelling in mathematics education - discussion document. Zentralblatt fur Didaktik der Mathematik 34 (5), 229-239.

Janks, H. (2004) The access paradox. English in Australia 139 (1), 33-42.

Khuzwayo, B. (2005) A history of mathematics education research in South Africa: The apartheid years. In R. Vithal, J. Adler and C. Keitel (eds) Researching Mathematics Education in South Africa (pp. 307-327). Cape Town: HSRC.

Lemke, J.L. (1990) Talking Science: Learning, Language and Values. Norwood, NJ: Ablex Publishing.

Lerman, S. and Zevenbergen, R. (2004) The socio-political context of the mathematics classroom. Using Bernstein's theoretical framework to understand classroom communities. In P. Valero and R. Zevenbergen (eds) Researching the Socio-political Dimensions of Mathematics Education (pp. 27-42). Boston, MA: Kluwer Academic.

Monaghan, F. (2007) From corpus to curriculum: Mapping the mathematical langscape. Paper presented at the Second Annual Symposium on Teaching and Learning Mathematics/Science in Multilingual Classrooms. Johannesburg: University of Witwatersrand.

Moschkovich, J. (2002a) A situated and sociocultural perspective on bilingual mathematics learners. Mathematical Thinking and Learning 4 (2\&3), 189-212.

Moschkovich, J. (2002b) An introduction to examining everyday and academic mathematics practices. In M.E. Brenner and J. Moschkovich (eds) Everyday and Academic Mathematics Classrooms (pp. 1-11). Reston, VA: NCTM.

Nesher, P. and Hershkovitz, S. (1997) Real world knowledge and mathematical knowledge. In E. Pehkonen (ed.) Proceedings of the 21st Conference of the International Group for 
the Psychology of Mathematics Education 3 (3), 280-287. Helsinki: University of Helsinki, PME.

Nyabanyaba, T. (1999) Whither relevance? Mathematics teachers' discussion of the use of 'real-life' contexts in school mathematics. For the Learning of Mathematics 19 (3), 10-14.

Pennycook, A. (1996) Incommensurable discourses? Applied Linguistics 15 (2), 115-138.

Pimm, D. (1987) Speaking Mathematically: Communication in Mathematics Classrooms. London: Routledge.

Pinto, D. (2001) Directory of science, engineering and technology foundation programmes. Proceedings of the 'Indaba' of Science, Engineering and Technology Foundation Programmes. Johannesburg: University of Witwatersrand College of Science.

Scott, I. (2006) Inaugural lecture presented at the University of Cape Town, South Africa.

Setati, M. (2002) Language practices in intermediate multilingual mathematics classrooms. Unpublished PhD thesis, University of Witwatersrand, Johannesburg, South Africa.

Setati, M. (2005) Mathematics education and language. In R. Vithal, J. Adler and C. Keitel (eds) Researching Mathematics Education in South Africa (pp. 73-109). Cape Town: HSRC.

Sethole, G. (2003) Meaningful contexts and dead mock reality: Experiences in black and white maths classrooms. In S. Jaffer and L. Burgess (eds) Proceedings of the Ninth National Congress of the Association for Mathematics Education of South Africa (Vol.1, pp. 283-293). Cape Town: AMESA.

Sethole, I.G. (2005) Learner's perspectives on the incorporation of the everyday in mathematics. Unpublished PhD thesis, University of Witwatersrand, Johannesburg, South Africa.

Sfard, A., Nesher, P., Streefland, L., Cobb, P. and Mason, J. (1998) Learning mathematics through conversation: Is it as good as they say? [1]. For the Learning of Mathematics 18 (1), 41-51.

Sierpinska, A. (1995) Mathematics: 'In context', 'pure', or 'with applications'? For the Learning of Mathematics 15 (1), 2-15.

South African Human Rights Commission (2006) Report of the Public Hearing on the Right to Basic Education. Johannesburg: South African Human Rights Commission.

Street, B. (1993) Introduction: The new literacy studies. In B. Street (ed.) Cross-Cultural Approaches to Literacy (pp. 1-12). Cambridge: Cambridge University Press.

Street, B. (2005) The hidden dimensions of mathematical language and literacy. Language and Education 19 (2), 136-141.

Thomas, R. and Gerofsky, S. (1997) An exchange about word problems. For the Learning of Mathematics 17 (2), 21-23.

Tobias, B. (2006) Mathematical word problems: Understanding how secondary students position themselves. African Journal for Research in Mathematics, Science and Technology Education 10 (2), 1-14.

Verschaffel, L., Greer, B. and De Corte, E. (2000) Making Sense of Word Problems. Lisse: Swets \& Zeitlinger.

Visser, A. (2006) University of Cape Town alternative admissions research project, language statistics on MAM1005H class, 2004 and 2005. Unpublished raw data, University of Cape Town, South Africa.

Vithal, R. and Volmink, J. (2005) Mathematics curriculum research: Roots, reforms, reconciliation and relevance. In R. Vithal, J. Adler and C. Keitel (eds) Researching Mathematics Education in South Africa (pp. 3-27). Cape Town: HSRC.

Widdowson, H.G. (1998) The theory and practice of critical discourse analysis. Applied Linguistics 19 (1), 136-151.

Wyndham, J. and Säljö, R. (1997) Word problems and mathematical reasoning - a study of children's mastery of reference and meaning in textual realities. Learning and Instruction 7 (4), 361-382. 